\title{
Postharvest Dry Matter and Soluble Solids Content Prediction in d'Anjou and Bartlett Pear Using Near-infrared Spectroscopy
}

\author{
Alex Goke \\ Tree Fruit Research \& Extension Center, Washington State University, \\ Wenatchee, WA 98801
}

\author{
Sara Serra ${ }^{1}$ and Stefano Musacchi \\ Tree Fruit Research \& Extension Center, Washington State University, \\ Wenatchee, WA 98801; and Department of Horticulture, Washington State \\ University, Pullman, WA 99164
}

Additional index words. near-infrared spectroscopy, predictive model calibration, nondestructive, fruit quality, Pyrus communis

\begin{abstract}
Dry matter (DM) has recently been proposed as a new quality index for apple, inspiring similar investigations in other tree fruit crops. Near-infrared spectroscopy (NIR) enables the nondestructive estimation of DM and other quality attributes, although the accuracy and reliability of this technology on North American pear varieties remain untested. In this study, predictive NIR regression models were developed for nondestructive determination of postharvest DM and soluble solids content (SSC) in d'Anjou and Bartlett pears (Pyrus communis L.) using a commercially available NIR spectrometer. At calibration, models performed reliably with coefficients of determination $\left(R^{2}\right)$ of 0.940 (DM) and 0.908 (SSC) for model trained on d'Anjou pears and 0.860 (DM) and 0.839 (SSC) for model trained on Bartlett pears. Application of the models to independent validation datasets demonstrated acceptable performance with $R^{2}$ values ranging from 0.722-0.901 and 0.651-0.844 between measured and predicted DM and SSC values, respectively. Differences in performance can be attributed to the different DM and SSC values and maturity levels between the fruit used for model calibration and those in the validation datasets. Although not all models developed in this study were accurate enough for quantitative determinations, NIR devices may be useful for orchard management decisions and fruit sorting purposes.
\end{abstract}

Because of large variability in fruit maturity at harvest and subsequent eating quality, delivering consistency in fresh pear products remains a significant challenge to the industry (Kupferman et al., 2010). As such, a current

Received for publication 2 Jan. 2018. Accepted for publication $28 \mathrm{Feb} .2018$.

This research was supported by the Northwest Pear Bureau (NWPB) funds, award \#PR16-105.

We would like to thank Bob Gix and Blue Star Growers (Cashmere, WA) for orchard access, and Felix Instruments (Camas, WA) for user support and assistance. We also thank Angela Knerl, Ryan Sheick, Stefan Roeder, and Rachel Leisso for their technical contributions.

Authors' contributions: A.G., S.S., and S.M. substantially contributed to the conception, design of the work, to the acquisition, analysis, or interpretation of data for the work; to drafting the work or revising it critically for important intellectual content; to final approval of the version to be published. All authors are in agreement to be accountable for all aspects of the work in ensuring that questions related to the accuracy or integrity of any part of the work are appropriately investigated and resolved.

${ }^{1}$ Corresponding author. E-mail: sara.serra@wsu. edu. research priority is to advance the understanding and assessment of maturity and quality indices to strengthen product homogeneity and consumer acceptance (Pacific Northwest Pear Research Committee, 2016). One such measure that has recently garnered interest in the tree fruit industry is that of DM-the sum of soluble (sugar) and insoluble (starch) carbohydrates, proteins, minerals, and other compounds (cell walls, organic acids, fibers, etc.) that accumulate in a fruit throughout its development on the tree from the metabolization of photosynthates (Suni et al., 2000). It is defined here as the ratio of fruit dry weight to fresh weight and expressed as a percentage.

DM can be distinguished from established maturity and quality indices such as color, firmness, and SSC in that it accounts for starch that later metabolizes to soluble sugars during the ripening process. Measured at or before harvest, it can be used to predict future internal quality following extended periods of cold storage as has been shown in apples (McGlone et al., 2003), kiwifruit (Crisosto et al., 2012), and mangoes (Subedi et al., 2007, 2010).

DM has also been suggested to be a reliable indicator of eating quality. In "Royal
Gala" apple, Palmer et al. (2010) demonstrated significant increases in consumer liking, consumer acceptance, and purchase likelihood of high DM fruits compared with low DM fruits (DM in this case referred to as DM concentration and presented as $\mathrm{g} \cdot \mathrm{kg}^{-1}$ ). Similar relationships have since been characterized for sweet cherries and consumer acceptance (Escribano et al., 2017), avocados and consumer liking and purchase intent (Gamble et al., 2010), and kiwifruit and consumer acceptance, liking, and purchase intent (Crisosto et al., 2012; Harker et al., 2009; Jaeger et al., 2011).

Although a promising quality indictor, DM (and SSC) is traditionally a destructive measurement, requiring time and effort to be evaluated while resulting in loss of product, with both of these factors often promoting small sample sizes for testing. In the particular case of European pears (cv. Bartlett, d'Anjou, Bosc, etc.), which demonstrate erratic postharvest ripening patterns and temperature sensitivities during storage, the assessment of DM and SSC rapidly and nondestructively would greatly advance the ability to create a more homogenous product that can consistently satisfy the expectations of the consumer.

Near-IR (NIR, 700-2500 nm) spectroscopy, after decades of research and application, is now becoming equipped to measure these properties nondestructively with everincreasing accuracy and efficiency. The NIR method is grounded in the principle that many compounds express unique absorbance spectra in the IR range, to which corresponding combination and overtone absorbance bands are found in the visible and NIR region. Measuring these spectra using various reflectance, interactance, or transmission-based methods, NIR instrumentation is able to predict the relative composition of compounds in a tissue that exhibit identifying absorbance characteristics in the NIR range (dos Santos et al., 2013; Nicolai et al., 2007; Wang et al., 2015).

Spectrochemical analysis of sugar (sucrose, glucose, and fructose) reveals numerous absorption bands in the shortwave NIR range related to the $\mathrm{O}-\mathrm{H}$ and $\mathrm{C}-\mathrm{H}$ groups of these molecules (Golic et al., 2003). Water is also easily detected in this range. Thus, tissues high in water and carbohydrate content such as thin-peel fruit are ideal candidates for assessment of DM and SSC using NIR spectroscopy (Saranwong and Kawano, 2007).

Although many studies have approached DM prediction using NIR, namely, in apple (McGlone et al., 2002a, 2003; Palmer et al., 2010; Travers et al., 2014a), kiwifruit (McGlone and Kawano, 1998; McGlone et al., 2002b, 2007; Osborne et al., 1996); and mango (Anderson et al., 2017), few have addressed pear (Travers et al., 2014b). To our knowledge, no other study has investigated DM and SSC prediction by NIR spectroscopy in d'Anjou or Bartlett pears, the two leading cultivars in North America. Here, we evaluated whether NIR spectroscopy could be used 
Table 1. Descriptive statistics for hue angle $\left(\mathrm{h}^{\circ}\right)$, chroma $\left(\mathrm{C}^{*}\right)$, and chlorophyll content $\left(I_{\mathrm{AD}}\right)$ parameters measured from d'Anjou and Bartlett pears in the nearinfrared model calibration and external cross-validation datasets (Orchards 1, 2, and 3 consisting of d'Anjou/OHF87, d'Anjou/Bartlett seedling, and Bartlett/ OHF87, respectively).

\begin{tabular}{|c|c|c|c|c|c|c|c|c|c|c|c|c|c|}
\hline \multirow[b]{2}{*}{ Cultivar } & \multirow[b]{2}{*}{ Dataset } & \multicolumn{4}{|c|}{$\mathrm{h}^{\circ}$} & \multicolumn{4}{|c|}{$\mathrm{C}^{*}$} & \multicolumn{4}{|c|}{ Chlorophyll content $\left(I_{\mathrm{AD}}\right)$} \\
\hline & & $n$ & Mean \pm SD & Min & Max & $n$ & Mean \pm SD & Min & $\operatorname{Max}$ & $n$ & Mean \pm SD & Min & $\operatorname{Max}$ \\
\hline \multirow[t]{3}{*}{$\overline{\text { d'Anjou }}$} & Calibration & 200 & $104.29 \pm 11.77$ & 38.91 & 114.97 & 200 & $42.52 \pm 4.67$ & 25.11 & 50.80 & 200 & $1.69 \pm 0.34$ & 0.46 & 2.25 \\
\hline & Orchard 1 & 945 & $106.03 \pm 7.31$ & 84.55 & 116.11 & 945 & $44.63 \pm 2.05$ & 34.88 & 52.57 & 945 & $1.42 \pm 0.52$ & 0.17 & 2.23 \\
\hline & Orchard 2 & 218 & $108.17 \pm 5.97$ & 91.02 & 116.11 & 218 & $45.29 \pm 1.98$ & 40.46 & 52.08 & 218 & $1.57 \pm 0.49$ & 0.30 & 2.25 \\
\hline \multirow[t]{2}{*}{ Bartlett } & Calibration & 200 & $95.18 \pm 8.45$ & 63.71 & 110.00 & 200 & $47.10 \pm 2.34$ & 38.55 & 54.12 & 200 & $0.90 \pm 0.49$ & 0.00 & 2.15 \\
\hline & Orchard 3 & 398 & $94.39 \pm 3.43$ & 82.87 & 105.45 & 398 & $52.64 \pm 2.30$ & 41.92 & 57.02 & 400 & $0.36 \pm 0.25$ & 0.01 & 1.33 \\
\hline
\end{tabular}

Values: pear cultivar (cultivar); nature of dataset (dataset; model calibration or external validation from Orchards 1,2 , or 3); number of samples ( $n$ ); mean value and $\mathrm{SD}($ mean $\pm \mathrm{SD})$; minimum value $(\mathrm{min})$; and maximum value (max).

as a reliable predictor of postharvest DM and SSC in d'Anjou and Bartlett pears using a commercially available and hand-held NIR spectrometer.

\section{Materials and Methods}

Fruit material. Three collections of fruit belonging to two pear cultivars were used for this investigation. d'Anjou pears were sampled from the 2016 harvest of two blocks within a commercial orchard located in Cashmere, WA (lat. $47^{\circ} 52^{\prime} \mathrm{N}$, long. $120^{\circ} 51^{\prime} \mathrm{W}$ ). The first block ("Orchard 1") was composed of d'Anjou/OHF87 trees trained to central leader. The block was planted in 1998 at a spacing of $4.3 \mathrm{~m}$ (interrow $) \times 2.5 \mathrm{~m}(957$ trees $/$ ha $)$. The second block ("Orchard 2") was composed of d'Anjou trees grafted on Bartlett seedling and trained to open vase. Trees from Orchard 2 were planted in the 1970 s at a spacing of $6 \times$ $6 \mathrm{~m}$ (278 trees/ha). In this block, fruit were harvested from extreme internal and the external position of the canopy based on light interception to capture a broad range of fruit materials that characterize those large canopies (Rudell et al., 2017). Fruit intercepting more than $70 \%$ light were considered external, less than $30 \%$ were considered internal. Light measurements were based on methods described in Zhang et al. (2016). Bartlett pears sampled from the 2016 harvest of a commercial orchard in Monitor, WA (lat. $47^{\circ} 50^{\prime} \mathrm{N}$, long. $120^{\circ} 44^{\prime} \mathrm{W}$ ). The orchard ("Orchard 3") was planted in 2012 at $3.7 \mathrm{~m}$ (interrow) $\times 1.5 \mathrm{~m}$ spacing (1800 trees/ha) with trees grafted on OHF87 and trained to either a spindle or biaxis system. Fruit harvested from all orchards were held at $\approx 1{ }^{\circ} \mathrm{C}$ regular atmosphere storage until model calibration and quality analysis.

Following 3 and 6 months of cold storage, 100 fruit of d'Anjou and 100 fruit of Bartlett, respectively, were selected for NIR model calibration based on skin color and predicted DM and SSC obtained from a preliminary NIR model (not discussed) to ensure a broad range of values. d'Anjou fruit from Orchard 2 were retained solely for external model validation. A subsample of 50 d'Anjou fruit were allowed to ripen for $7 \mathrm{~d}$ at room temperature whereas the other 50 remained in cold storage to amplify the variability in the sample set. Bartlett pears were stored longer than the industry standard for this cultivar and the average $I_{\mathrm{AD}}$ of the fruit used

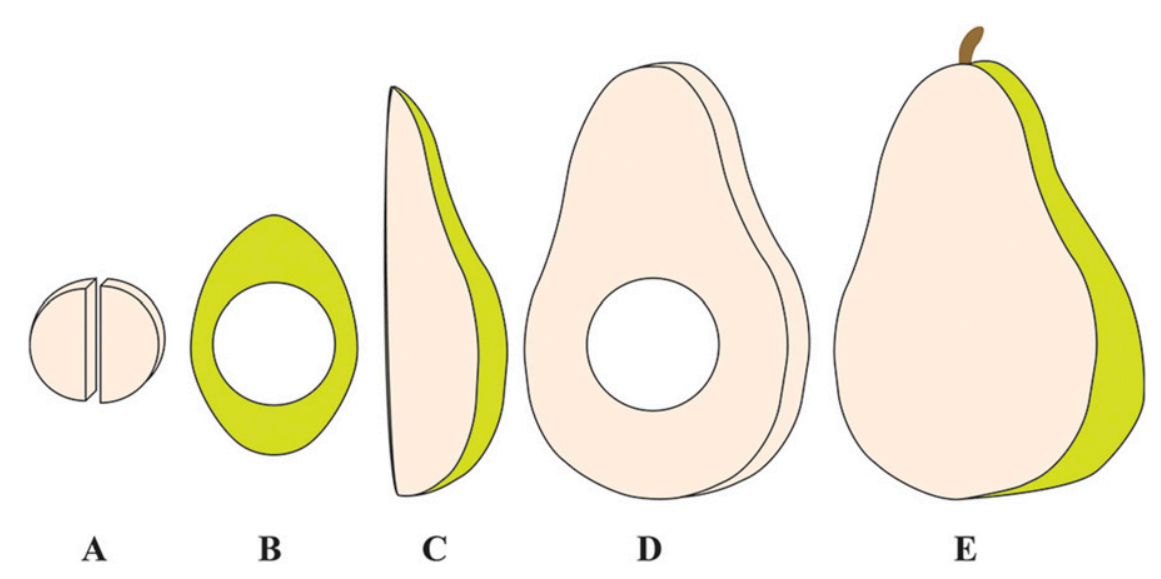

Fig. 1. Generalized depiction of the location of destructive dry matter (DM) and soluble solids content (SSC) measurements taken on the pear fruit. (A) $25 \mathrm{~mm}$ diameter, $10 \mathrm{~mm}$ depth tissue plug from which near-infrared measurements were collected. Half of the plug assessed for DM after removing the peel, the other for SSC. (B) Equatorial blush or shade side from which the plug was removed. (C) Vertical slice used in the determination of "whole-fruit" SSC. (D) Vertical slice used in the determination of "whole-fruit" DM. (E) Fruit material on opposing face from which A-C were sampled (not shown). Figure to be produced in color online only.

in calibration was 0.90 (Table 1 , Ziosi et al., 2008) indicating ripe fruit, and therefore Bartlett fruit were not ripened further at room temperature, although the fruit were still suitable for use with little internal defects. The resulting sample pools were thus broadly representative of d'Anjou and Bartlett cultivars in terms of postharvest maturity following cold storage.

Spectral measurements. Interactance spectra of a $25 \mathrm{~mm}$ diameter circle drawn on opposing equatorial red-blushed (the face suspected to have received the most sun) and shade cheeks of each fruit was obtained using the portable Felix F-750 Produce Quality Meter (Felix Instruments, Camas, WA). Equipped with a Zeiss MMS1 VIS-NIR spectrometer, the Felix F-750 measures the spectra every $3 \mathrm{~nm}$ across a $310-1100 \mathrm{~nm}$ range to a resolution of 8-13 $\mathrm{nm}$. Reflectance was obtained by the subtraction of a shuttered reference measurement and then calculated as absorbance by $\log (1 /$ Reflectance $)$. Four scans were obtained simultaneously to produce one average absorbance spectra for each scan area. To account for any potential temperature-influenced spectrochemical deviations, measurements were taken across three internal fruit temperatures obtained by bringing fruit to thermal equilibrium at $\approx 1$, 20 , and $30{ }^{\circ} \mathrm{C}$. Each face was ultimately represented by three scans (one at each temperature), with two faces per fruit, for a total of 600 spectra per 100 -fruit model calibration dataset.

Fruit quality analysis. Skin color within each NIR scan area was assessed using a Minolta colorimeter (Minolta CR-300; Tokyo, Japan). Color data were captured in triplet within the scan area in the CIELAB color space, averaged, and expressed as hue angle $\left(\mathrm{h}^{\circ}\right)$ and chroma $\left(\mathrm{C}^{*}\right)$ following McGuire (1992). Chlorophyll content was estimated within each scan area by measuring the index of absorbance difference $\left(I_{\mathrm{AD}}\right)$ at 670 and $720 \mathrm{~nm}$ (Ziosi et al., 2008) using a DA Meter (Sinteleia, Bologna, Italy).

For destructive DM and SSC determinations, a $10 \mathrm{~mm}$ in depth tissue plug of the $25 \mathrm{~mm}$ diameter NIR scan area was removed from opposing blush and shade cheeks of each fruit and the peel removed. Half of the plug was evaluated destructively for DM whereas the other was evaluated destructively for SSC. To account for any potential DM and SSC gradients within the fruit (as shown to be present in apple by Perring, 1989 ), an $\approx 15-25 \mathrm{~g}$ vertical slice from stem to calyx through the core of the fruit was taken and the peel, core, and woody stem and calyx areas removed to destructively evaluate "whole-fruit" DM, and two opposing vertical wedges from blush and shade sides to destructively evaluate "whole-fruit" SSC 
(Fig. 1). Destructive DM was obtained by oven-drying the sample at $60{ }^{\circ} \mathrm{C}$ until constant dry weight was achieved and is expressed as a percentage of the fresh weight. Destructive SSC was evaluated using a temperature-compensating refractometer on the juices expelled from a filter-lined garlic press (PAL-1; ATAGO USA Inc., Bellevue, WA).

Model calibration and validation. Calibration of DM and SSC prediction models for d'Anjou and Bartlett pears was conducted within the Model Builder software environment accompanying the F-750 Produce Quality Meter (Version 1.1.0.105; Felix Instruments). As both sides of each fruit were evaluated independently of each other, the effective sample size used in calibration was $n=200$ for both models. Partial least squares regression was used to correlate destructive measurements to DM and SSC predictions based on second derivative absorbance in the
729-975 nm range. Cross-validation was conducted automatically by the Model Builder software during model calibration by removing one sample from the calibration dataset and predicting said sample using the resulting model to simulate an independent dataset (i.e., "leave-one-out"). Models were calibrated using the fewest number of components without undermining performance as judged by the root mean square error of crossvalidation (RMSECV). Independent datasets from quality analysis carried out on fruit from the 2016 harvest of Orchards 1, 2, and 3 were implemented as external cross-validation datasets $(n=945,218$, and 400 fruit, respectively). In these external datasets, fruit were assessed after 5-7 d of room temperature $\left(20\right.$ to $\left.23{ }^{\circ} \mathrm{C}\right)$ ripening either at harvest (less than 1 month of cold storage) or following 6 months of cold storage. In these sets, NIR predictions of DM and SSC in the opposing faces of each fruit taken at room temperature and $I_{\mathrm{AD}}$ were averaged together to provide one estimation per fruit. Peel color measurements were taken once from the most representative nonblush (i.e., background, most green) region of each fruit. Destructive DM and SSC values were obtained following the "whole-fruit" method only. Although SSC was assessed individually for each fruit, destructive DM determination was conducted on a subsample of $\approx 25 \%$ of the fruit.

Model performance in respect to calibration was evaluated based on its $R^{2}$, coefficient of determination of cross-validation $\left(R_{\mathrm{cv}}{ }^{2}\right)$, root mean square error of prediction (RMSEP), RMSECV, mean absolute error (MAE) between actual and predicted values, the ratio of the dataset SD to RMSEP (RPD, Nicolai et al., 2007), and the ratio of the dataset interquartile range to RMSEP (RPIQ, Bellon-Maurel et al., 2010).

Table 2. Descriptive statistics for dry matter (DM, \%) and solid solids content (SSC, \%) destructively measured from d'Anjou and Bartlett pears in the nearinfrared model calibration and external cross-validation datasets (Orchards 1, 2, and 3 consisting of d'Anjou/OHF87, d'Anjou/Bartlett seedling, and Bartlett/ OHF87, respectively).

\begin{tabular}{|c|c|c|c|c|c|c|c|c|c|}
\hline \multirow[b]{2}{*}{ Cultivar } & \multirow[b]{2}{*}{ Dataset } & \multicolumn{4}{|c|}{$\mathrm{DM}(\%)$} & \multicolumn{4}{|c|}{ SSC (\%) } \\
\hline & & $n$ & Mean \pm SD & Min & $\operatorname{Max}$ & $n$ & Mean \pm SD & Min & $\operatorname{Max}$ \\
\hline \multirow[t]{3}{*}{$\overline{\text { d'Anjou }}$} & Calibration & 200 & $15.49 \pm 1.47$ & 11.06 & 19.51 & 200 & $13.77 \pm 1.39$ & 9.30 & 17.30 \\
\hline & Orchard 1 & 203 & $15.55 \pm 1.58$ & 8.23 & 19.55 & 944 & $13.69 \pm 1.13$ & 10.00 & 17.30 \\
\hline & Orchard 2 & 75 & $15.74 \pm 2.07$ & 12.01 & 20.14 & 217 & $13.98 \pm 1.82$ & 9.70 & 18.50 \\
\hline \multirow[t]{2}{*}{ Bartlett } & Calibration & 200 & $11.02 \pm 1.05$ & 9.00 & 14.75 & 200 & $9.07 \pm 1.07$ & 7.00 & 12.50 \\
\hline & Orchard 3 & 120 & $13.94 \pm 1.64$ & 9.97 & 17.42 & 382 & $12.56 \pm 1.44$ & 8.40 & 15.70 \\
\hline
\end{tabular}

Values: pear cultivar (cultivar); nature of dataset (dataset; model calibration or external validation from Orchards 1,2 , or 3 ); number of samples ( $n$ ); mean value and $\mathrm{SD}$ (mean $\pm \mathrm{SD}$ ); minimum value (min); and maximum value (max).

\section{Dry Matter (DM)}

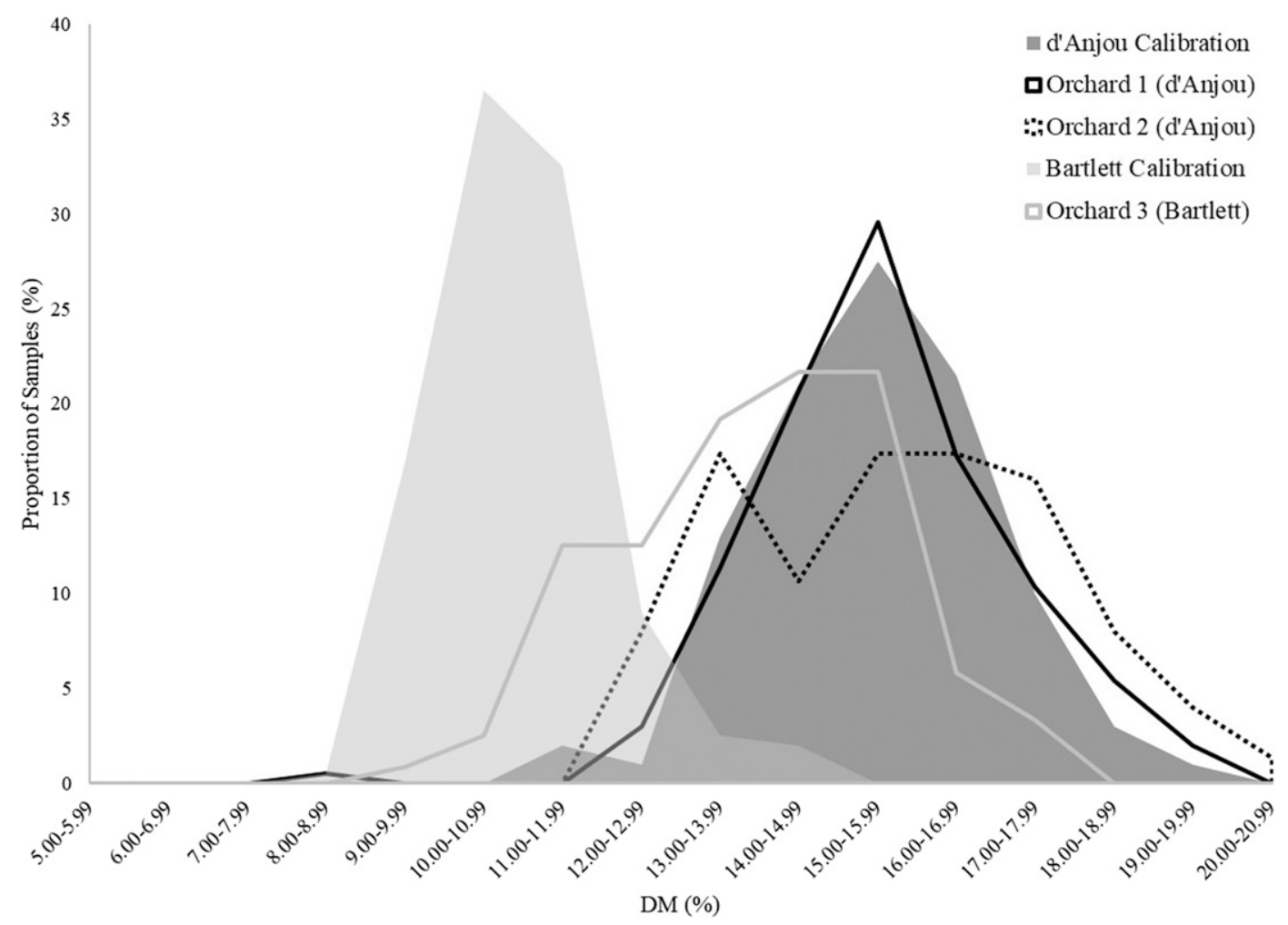

Fig. 2. Distribution of dry matter (DM, \%) values destructively measured from d'Anjou and Bartlett pears in the near-infrared model calibration (shaded areas) and external cross-validation datasets (solid and dashed lines; Orchards 1, 2, and 3 consisting of d'Anjou/OHF87, d'Anjou/Bartlett seedling, and Bartlett/OHF87, respectively). 
Additional analysis was conducted using the SAS 9.4 statistical analysis package (2013 SAS Institute, Cary, NC). Student-Newman-Keuls (SNK) means separation tests were performed on second derivative absorbance spectra obtained during model calibration to investigate temperature effects on absorbance. Linear regression analysis (PROC REG) was implemented to evaluate model performance on the external validation datasets based on its $R^{2}$, RMSEP, MAE between actual and predicted values, RPD, and RPIQ.

Influence of NIR sample area on prediction accuracy. Peiris et al. (1999) and Perring (1989) observed significant spatial variability in DM and SSC in a number of fresh fruit and vegetables, including apples. To investigate the potential gradient of DM and SSC in pear, linear regression analysis (PROC REG) was implemented to correlate destructive "whole-fruit" DM and SSC (vertical slice taken from the center of the fruit for DM, opposing vertical wedges for SSC, Fig. 1) to the blush, shade, and averaged blush and shade values in the calibration dataset. In terms of NIR sensor placement, predicted blush face, shade face, and averaged predicted blush and shade DM and SSC were compared with the same destructive measures in the calibration datasets (predictions averaged across three fruit temperatures) and to destructive "whole-fruit" values only in the external validation sets. The best-fitting model corresponding to the variety of the dataset was used for generating predicted values (i.e., d'Anjou model for Orchard 1 and Orchard 2, Bartlett model for Orchard 3). Comparisons were evaluated based on the $R^{2}$, root mean square error (RMSE), and MAE.

\section{Results}

Fruit material characteristics. d'Anjou and Bartlett pears used in model calibration and external cross-validation exhibited a wide spectrum of coloration ( $\mathrm{h}^{\circ}$ and $\mathrm{C}^{*}$ ), chlorophyll content $\left(I_{\mathrm{AD}}\right)$, destructive $\mathrm{DM}$, and destructive SSC (Tables 1 and 2). Bartlett fruit on average exhibited lower $I_{\mathrm{AD}}$ values in both model calibration and external crossvalidation datasets relative to d'Anjou fruit. Bartlett fruit were also lower on average in $\mathrm{h}^{\circ}$ (values represent the color range from green to yellow to red at 180,90 , and $0^{\circ}$, respectively) and higher in $\mathrm{C}^{*}$ (higher values indicate more saturation of the $h^{\circ}$ ). Figures 2 and 3 illustrate the distribution of destructive DM and SSC values specifically within each calibration and validation dataset. Bartlett fruit used in model calibration were noticeably lower in both DM and SSC ranges than d'Anjou calibration fruit, and both Bartlett and d'Anjou fruit used in external crossvalidation.

Spectral characteristics. Based on manufacturer recommendations, the optimal spectral range for model calibration was determined to be that of 729-975 nm, similar to those implemented in other DM and SSC NIR investigations (Escribano et al., 2017). Regions outside of this window were noisy and uninformative likely because of the absorbance by chlorophyll and other pigmentation in the visible range $(400-700 \mathrm{~nm})$. Within the 729 $975 \mathrm{~nm}$ range, spectra were generally smooth with several absorbance peaks at $\approx 819,837$, 924, and $960 \mathrm{~nm}$ for both d'Anjou and Bartlett varieties (Figs. 4-6).

Absorbance among the three fruit temperatures were each significantly different from one other along nearly the entire spectral window used in model calibration for both d'Anjou and Bartlett variety models (SNK, $P<0.05$, Figs. 4 and 5). Regions of nonsignificance centered around wavelengths at which ordering of the absorbance bands reverses in respect to intensity, namely, 759, 855 (nonsignificant in Bartlett model only), and $930 \mathrm{~nm}$. Generally, absorbance intensified from low to high fruit temperatures, the differences (Figs. 4 and 5) most pronounced at peaks centered $\approx 738,837,918$, and $960 \mathrm{~nm}$. Absorbance bands were often significantly different between varieties as well (SNK, $P<0.05$, Fig. 6). Notable differences are found between 729-762, 912-939, and 954-975 nm.

Model calibration. The optimal number of components for the d'Anjou model were determined as seven for both DM and SSC, and nine for DM and eight for SSC for the Bartlett model. Among all models, $R^{2}$ ranged

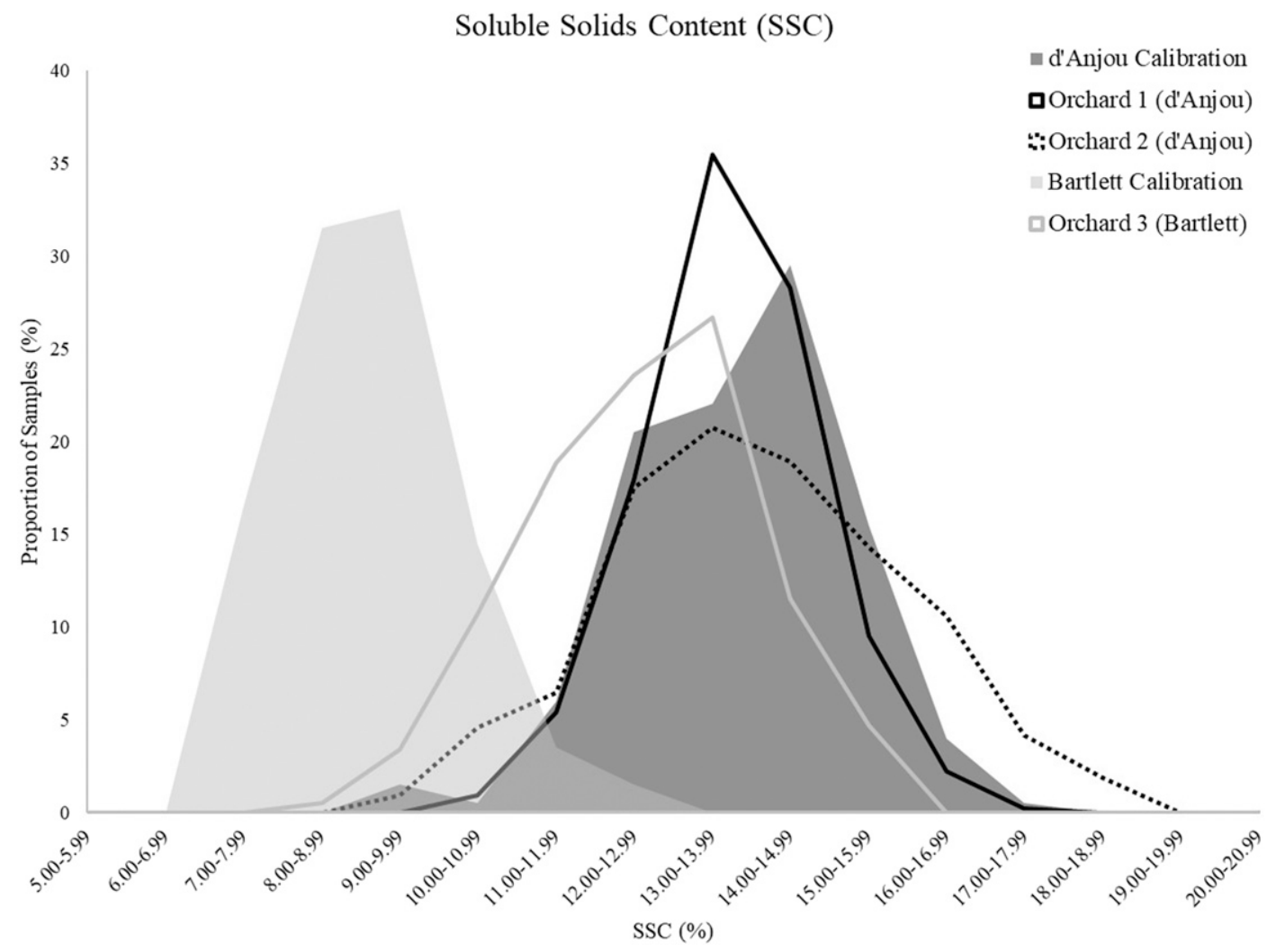

Fig. 3. Distribution of soluble solids content (SSC, \%) values destructively measured from d'Anjou and Bartlett pears in the near-infrared model calibration (shaded areas) and external cross-validation datasets (solid and dashed lines; Orchards 1, 2, and 3 consisting of d'Anjou/OHF87, d'Anjou/Bartlett seedling, and Bartlett/OHF87, respectively). 
from 0.839 to 0.940 , RMSEP from 0.360 to 0.429 , MAE from 0.282 to 0.334 , RPD from 2.490 to 4.083 , and RPIQ from 3.321 to 5.594 (Fig. 7; Table 3). DM models performed better than SSC models in all aspects (lower RMSEP and RMSECV, higher $R^{2}$ and $R_{\mathrm{cv}}{ }^{2}$, lower MAE, and higher RPD and RPIQ). The d'Anjou DM model was the strongest performing model $\left(\mathrm{RMSEP}=0.360, R^{2}=\right.$ $0.940, \mathrm{MAE}=0.282, \mathrm{RPD}=4.083$, and RPIQ $=$ 5.594), whereas the Bartlett SSC was the weakest $\left(\mathrm{RMSEP}=0.429, R^{2}=0.839, \mathrm{MAE}=\right.$ 0.334 , RPD $=2.490$, and RPIQ $=3.321$ ), although still considered acceptable in terms of performance.

Influence of NIR sample area on prediction accuracy. The fruit area sampled for destructive measurement had dramatic impacts on the resulting DM and SSC determinations. Absolute differences in DM between the blush and shade side of pooled Bartlett and d'Anjou fruit ranged from $0 \%$ to $3.044 \%$ (average $0.620 \%$ ) and $0-2.400 \%$ (average $0.574 \%$ ), respectively, for SSC, with the blush face higher on average in DM and SSC than the shade side. In the d'Anjou and Bartlett model calibration datasets, DM and SSC destructively determined from vertical "whole-fruit" slices differed from the destructive measurements taken on either blush and shade faces as well (Table 4). Although the blush side was a closer estimation of "Whole-Fruit" DM and SSC than was the shade side in terms of MAE, averaging measurements taken from opposing blush and shade sides of the fruit resulted in significantly less error than either fruit face (SNK, $P<0.05$, Table 4).

As for the pooled calibration models of both cultivars, absolute differences in predicted values between blush and shade side of fruit ranged from $0 \%$ to $3.502 \%$ for DM, and from $0 \%$ to $2.964 \%$ for SSC, with the blush face higher on average in DM and SSC than the shade side. As with the destructive measurements, averaging the NIR predictions of blush and shade faces also provided the best estimation of "Whole-Fruit" destructive DM and SSC (Table 4).

External cross-validation. Results of model performance criteria in respect to the external validation datasets are shown in Table 5. Actual vs. predicted parameter plots are shown in Figs. 8 and 9. Again, DM models largely performed better across validation sets than SSC models did, and the
d'Anjou model generally performed better than the Bartlett model (lower RMSEP and RMSECV, higher $R^{2}$ and $R_{\mathrm{cv}}{ }^{2}$, lower MAE, and higher RPD and RPIQ). Models also performed better on the cultivar they were trained on. In the Orchard 3 validation set, however, both models performed comparably. Model performance varied depending on postharvest maturity of the fruit as well, with both Bartlett and d'Anjou DM models generally performing better on fruit material subjected to 6 months of cold storage with the exception of Orchard 2 material, where DM models applied to fruit subjected to only 1 month of cold storage were superior. SSC models showed no clear pattern in performance between fruit storage periods among orchards. Pooling the validation sets, d'Anjou model is clearly superior to Bartlett model in all aspects, with RMSEP of 0.821 and $1.078, R^{2}$ of 0.806 and $0.666, \mathrm{MAE}$ of 0.649 and 1.530, and RPD of 2.268 and 1.728 between d'Anjou and Bartlett DM models, respectively, and RMSEP of 0.683 and $0.843, R^{2}$ of 0.770 and 0.651 , MAE of 0.520 and 2.260, and RPD of 2.087 and 1.691 between d'Anjou and Bartlett SSC models, respectively (Table 5).

\section{Temperature Effects on Absorbance - d'Anjou}

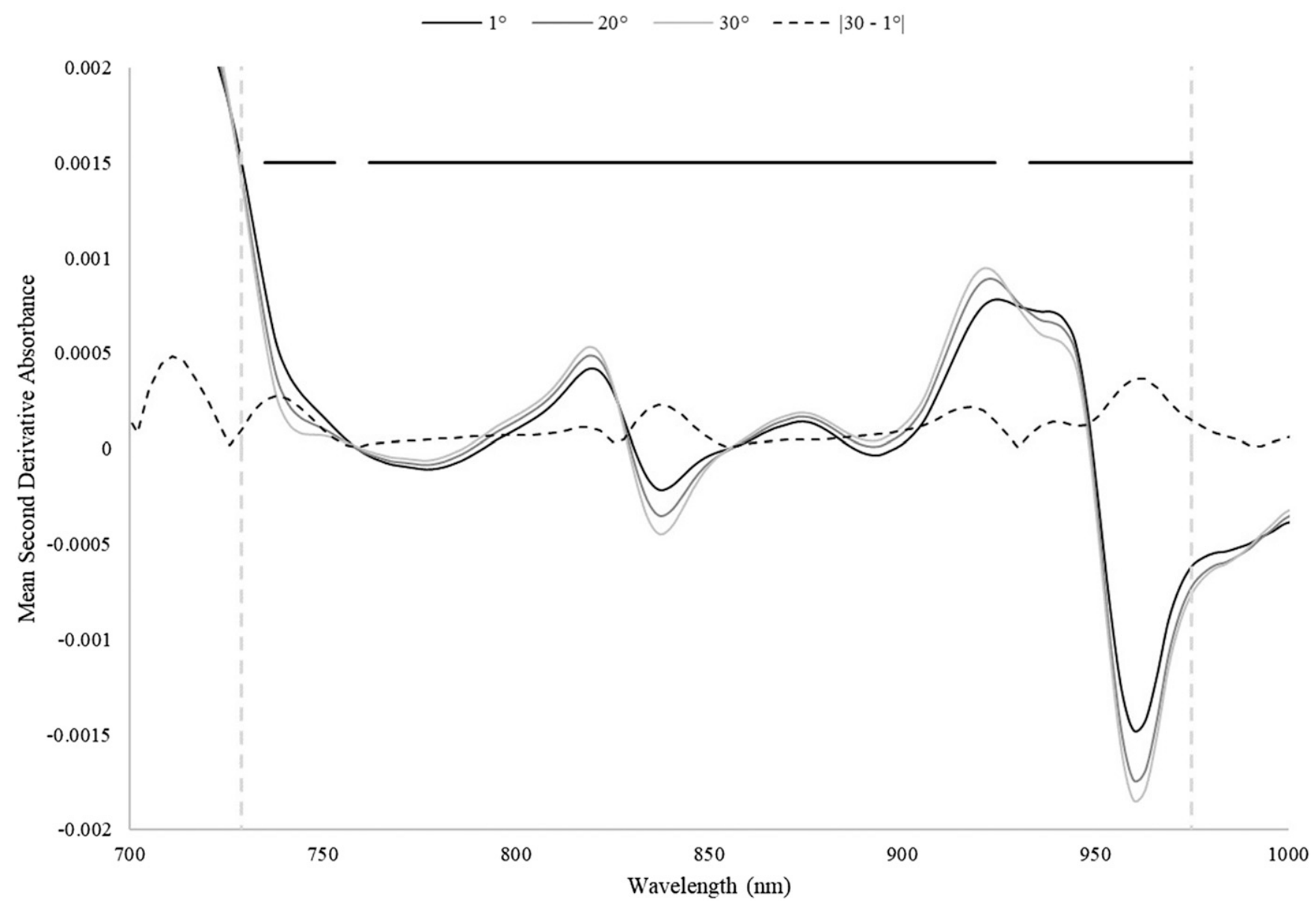

Fig. 4. Average second derivative absorbance spectra among three internal fruit temperatures $\left(1{ }^{\circ} \mathrm{C}\right.$ black, $20{ }^{\circ} \mathrm{C}$ gray, and $30^{\circ} \mathrm{C}$ light gray) measured at d'Anjou cultivar model calibration. Dashed horizontal line shows absolute difference in second derivative absorbance between 30 and $1{ }^{\circ} \mathrm{C}$; vertical lines depict spectral range used in model calibration $(729-975 \mathrm{~nm}$ ); solid horizontal line illustrates near-infrared regions where average second derivative absorbance bands are statistically unique from one another (Student-Newman-Keuls, $P<0.05$ ). 


\section{Discussion}

One of the underlying motivations of this study was to engage the issue of inconsistencies in fresh d'Anjou and Bartlett pear quality by evaluating if NIR could be used to nondestructively detect differences in postharvest internal quality. Considering purely some of the traditional quality measurements of color, $I_{\mathrm{AD}}$, and SSC, clear differences were present in the fruit material used. Because of modifications in location of measurement of color and $I_{\mathrm{AD}}$ parameters between calibration and external crossvalidation fruit, statistical inferences cannot soundly be made from the data presented in Table 1 and Figs. 2 and 3. However, it is clear that both varieties had internal quality differences that were not observable from surface features. For instance, d'Anjou fruits harvested from the extreme internal and external positions of the canopy ("Orchard 2") had a broader, more plateaued distribution of DM and SSC values relative to those harvested randomly from the canopy in Orchard 1, which showed a bell-shaped distribution with most values clustered in the middle. As for Bartlett, DM and SSC values were lower in the calibration set relative to the external validation set. These differences are most likely the result of the additional ripening time allowed for the external validation fruit at harvest and after storage, whereas the fruit used in calibration were determined already ripe after storage and were not ripened further. The notable variation in DM and SSC among the fruit material underpins the need for nondestructive determinations of internal quality parameters to ensure homogeneity in fresh pear products to meet consumer's expectations.

During model calibration, several interesting aspects of the NIR second derivative absorbance spectra were observed (Figs. 4-6). The range of 725-975 nm proved most informative in the determination of DM and SSC, exhibiting smooth spectra with several peaks at $\approx 819,837,924$, and 960 $\mathrm{nm}$, similar to the features reported in other studies using the Felix F-750 instrument on cherries (Escribano et al., 2017; Toivonen et al., 2017). Spectra were highly convoluted beyond this range in either direction, likely because of absorbance by pigments and other interfering compounds. The strong absorption peak at $960 \mathrm{~nm}$ can be attributed to absorption by both water and sugar, although the peak $\approx 924 \mathrm{~nm}$ is likely a result of overlapping absorption by sugars alone at 910 and $930 \mathrm{~nm}$ (Golic et al., 2003).

Unsurprisingly, spectra were highly divergent (and statistically distinct) in several regions when separated by temperature, with each variety appearing equally sensitive (Figs. 4 and 5). Differences were most apparent at peaks centered $\approx 738,837,918$, and $960 \mathrm{~nm}$. As reported by Kawano et al. (1995), difference in spectra of water between 21 and $31{ }^{\circ} \mathrm{C}$ show similar peaks $\approx 842$ and $966 \mathrm{~nm}$, suggesting that a large portion of temperature variations in absorption observed here at 837 and $960 \mathrm{~nm}$ are because of decreases in hydrogen bonding in water associated with increases in temperature (Golic et al., 2003). Escribano et al. (2017) thoroughly demonstrated the impacts of temperature on NIR model performance-models developed under temperature conditions different from those when it is applied greatly reduce model

\section{Temperature Effects on Absorbance - Bartlett}

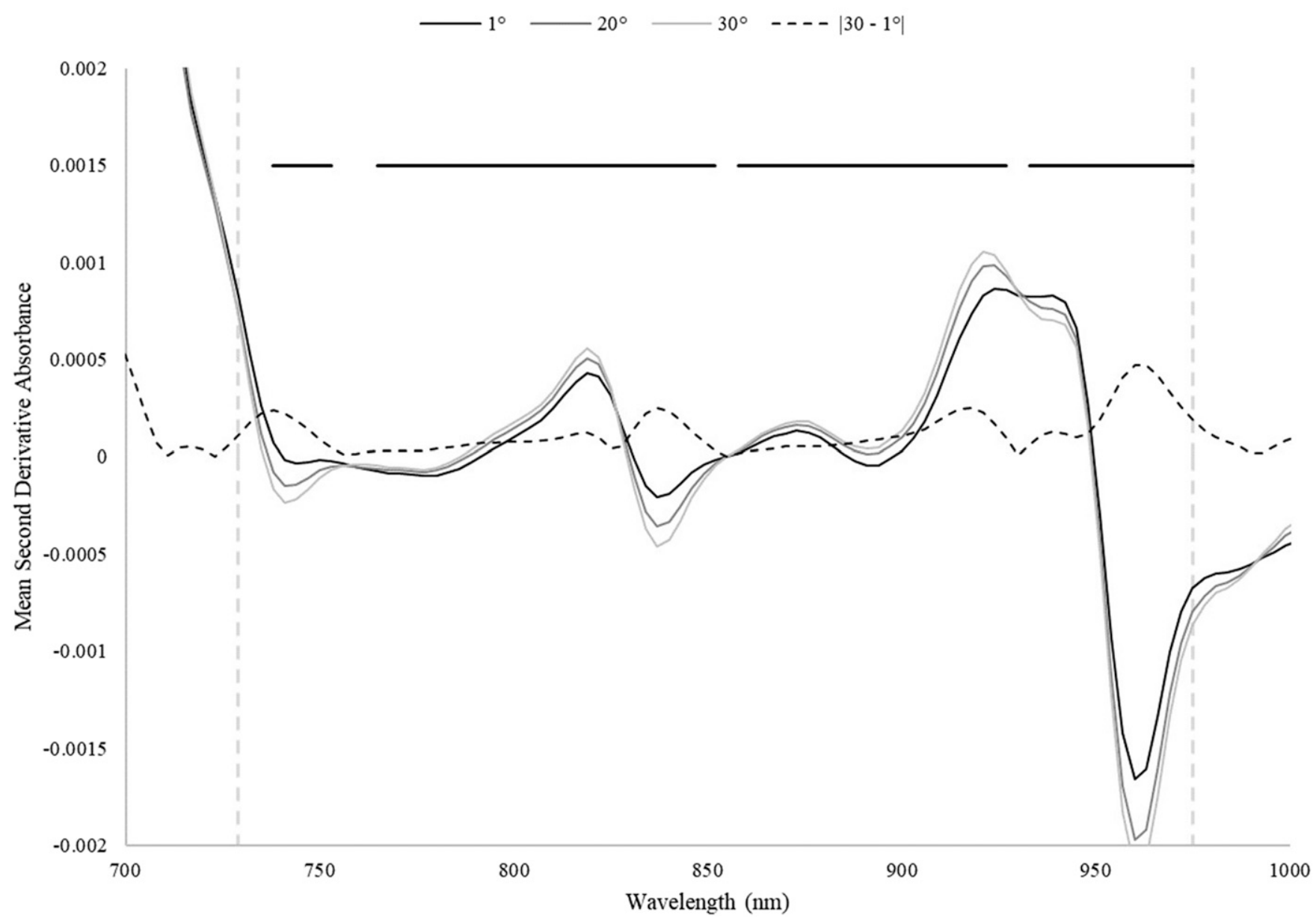

Fig. 5. Average second derivative absorbance spectra among three internal fruit temperatures $\left(1^{\circ} \mathrm{C}\right.$ black, $20^{\circ} \mathrm{C}$ gray, and $30^{\circ} \mathrm{C}$ light gray) measured at Bartlett cultivar model calibration. Dashed horizontal line shows absolute difference in second derivative absorbance between 30 and $1{ }^{\circ} \mathrm{C}$; vertical lines depict spectral range used in model calibration $(729-975 \mathrm{~nm}$ ); solid horizontal line illustrates near-infrared regions where average second derivative absorbance bands are statistically unique from one another (Student-Newman-Keuls, $P<0.05$ ). 
accuracy. Therefore, thoughtful consideration should be taken during model calibration to best mimic the environment under which the model is destined to be implemented, or, as performed here, multiple temperatures should be taken into account to ensure flexibility in application from the field, cold room, and possible conditions inbetween. The present results represent a novelty in respect to the study published by Travers et al. (2014b) on cv. 'Clara Frijs' pears where no temperature effect was taken in consideration. Our ultimate goal is to build cultivar-specific models for PNW pear varieties that could be adopted in all the steps of the fruit supply chain to nondestructively predict DM from the field (at high temperatures) to sorting (room temperature) to storage (low temperature) and therefore it is necessary to compensate for temperature variations in model calibrations as we did here.

Interestingly, average spectra between d'Anjou and Bartlett were often statistically unique from one another as well regardless of temperature, with large deviations surrounding $960 \mathrm{~nm}$ and below $760 \mathrm{~nm}$ (Fig. 6). Water content associated with DM and SSC values (Bartlett being dramatically lower than d'Anjou at calibration in these respects) affecting the absorbance at $960 \mathrm{~nm}$ may partially explain the spectral deviations observed, but other divergent regions of the spectra are not clearly resolved by this reasoning.

Model performance following calibration and external cross-validation was mostly acceptable for all models. DM models performed better than SSC models in nearly all regards both at calibration and external crossvalidation (Tables 3 and 5), likely because of the inability of NIR to discriminate between various forms of carbohydrate (Travers et al., 2014a). This limitation favors DM as a parameter that is better equipped for NIR estimation over SSC, as both forms are aggregated in the measure where SSC seeks only the soluble carbohydrates in the form of sugar.

One poor performing model we observed was the Bartlett model when applied to external cross-validation datasets. The large disjunction of DM and SSC values between the calibration and validation sets for Bartlett (Figs. 2 and 3) likely contributed to the poorer performance, as the model was not equipped to predict values higher than it was calibrated for, indicated by the near constant underprediction compared with destructive values (Figs. 8 and 9). The d'Anjou model performed acceptably regardless of implementation, indicating a model developed on one cultivar may reliably be used on other varieties as other studies have suggested (Escribano et al., 2017; Toivonen et al., 2017). However, the best performing model for either cultivar was ultimately the model calibrated on that variety, and applying a model calibrated to another variety or orchard consistently resulted in loss of model accuracy to varying degrees. The magnitude of this loss appears to be related to the difference in DM and SSC values between calibration fruit and those the model is applied to- one would need to be certain that distributions of DM and SSC values the model is intended to measure do not exceed the range of values the model was trained on to avoid large losses in accuracy. Considering also the significant deviations found between d'Anjou and Bartlett calibration spectra, further investigation is

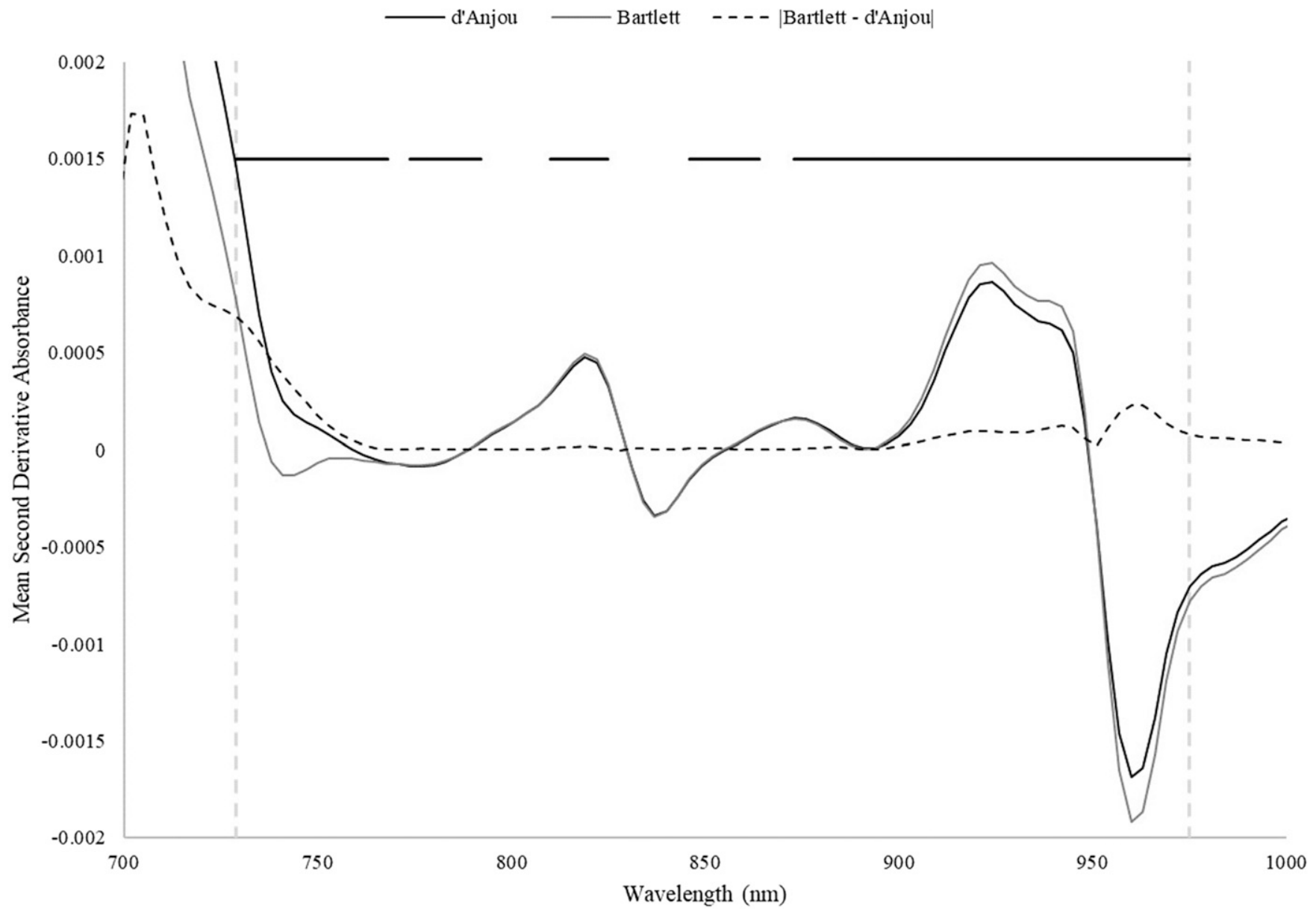

Fig. 6. Average second derivative absorbance spectra between d'Anjou (black) and Bartlett (gray) pears measured at model calibration. Dashed horizontal line shows absolute difference in second derivative absorbance between the varieties; vertical lines depict spectral range used in model calibration (729-975 nm); solid horizontal line illustrates near-infrared regions where average second derivative absorbance bands are statistically unique from one another (StudentNewman-Keuls, $P<0.05$ ). 
needed to understand any potential cultivarspecific influences on NIR models in pear.

Applying the predictive models to fruit of different maturity stages also affected prediction accuracy. For DM models applied to external validation datasets, fruit evaluated at harvest ( 1 month of regular air cold storage) were generally predicted to have lower DM relative to fruit evaluated following 6 months of storage (Fig. 8). Indeed, DM models generally performed better on fruit that were stored for 6 months compared with at-harvest fruit with lower RMSEP, higher $R^{2}$, lower MAE, and higher RPD and RPIQ values with the exception of Orchard 2 fruit (Table 5). This is likely because of only poststorage fruit being used for NIR model calibration for both cultivars, reducing the model effectiveness beyond strictly poststorage applications. SSC models did not display clear patterns of prediction bias or accuracy of models applied at harvest or after storage (Fig. 9; Table 5), although differences did still exist among applications. Clearly, model calibration fruit maturity, in addition to the DM and SSC values of the fruit, is an important determinant of model flexibility and should be considered during calibration. Further work is needed to investigate acceptable thresholds of model performance outside of the calibration environment before harvest, after harvest, and after cold storage and ripening.

The location of spectra acquisition on the fruit played a striking role in the accuracy of predicting "Whole-Fruit" DM and SSC (Table 4). More than 3\% of difference in DM and 2.4 of SSC were observed in the calibration fruit between blushed and shaded opposing faces, with the blush side typically higher in both DM and SSC than the shaded side. This observation aligns with the results of Torres et al. (2013) and Zhang et al. (2016) who demonstrated that sun exposure positively influenced SSC in apples and pears, respectively. It is apparent that these trends may apply to variable
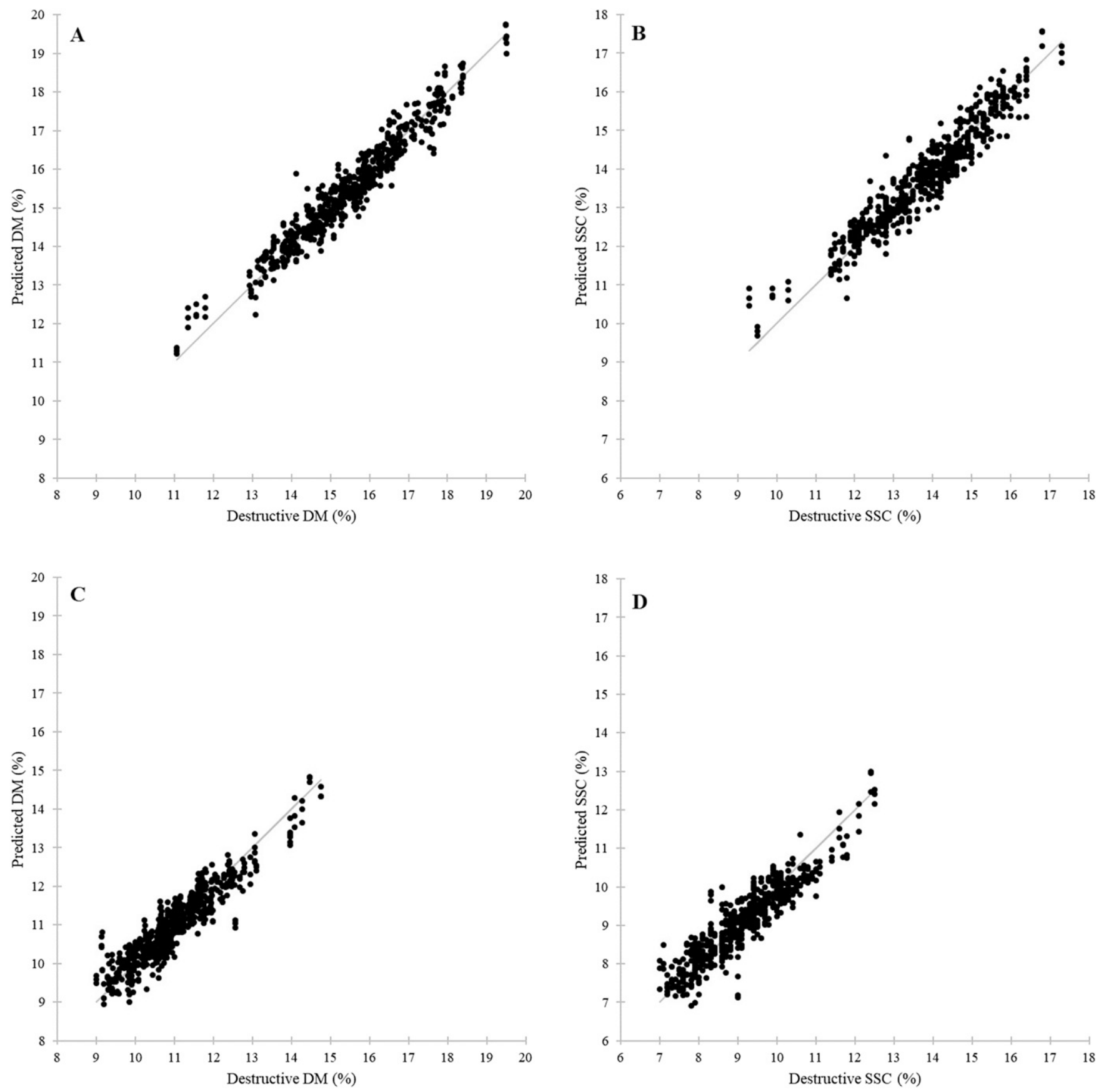

Fig. 7. Destructive vs. predicted values of (A) dry matter (DM) at d'Anjou model calibration, (B) soluble solids content (SSC) at d'Anjou model calibration, (C) DM at Bartlett model calibration, and (D) SSC at Bartlett model calibration. Reference line illustrates a 1:1 prediction of the destructive value. 
Table 3. Performance statistics for dry matter (DM) and soluble solids content (SSC) models developed for d'Anjou and Bartlett variety pear.

\begin{tabular}{|c|c|c|c|c|c|c|c|c|c|c|}
\hline Cultivar & Trait & $n$ & Components & RMSEP & $R^{2}$ & RMSECV & $R_{\mathrm{cv}}{ }^{2}$ & MAE & RPD & $\overline{\mathrm{RPIQ}}$ \\
\hline \multirow[t]{2}{*}{$\overline{\text { Bartlett }}$} & DM & 200 & 9 & 0.394 & 0.860 & 0.440 & 0.825 & 0.308 & 2.671 & 3.348 \\
\hline & $\mathrm{SSC}$ & 200 & 8 & 0.429 & 0.839 & 0.462 & 0.813 & 0.334 & 2.490 & 3.321 \\
\hline \multirow[t]{2}{*}{ d'Anjou } & DM & 200 & 7 & 0.360 & 0.940 & 0.379 & 0.934 & 0.282 & 4.083 & 5.594 \\
\hline & $\mathrm{SSC}$ & 200 & 7 & 0.422 & 0.908 & 0.445 & 0.897 & 0.330 & 3.290 & 4.501 \\
\hline
\end{tabular}

Values: number of samples $(n)$; number of components (Components, \#), root mean square error of prediction (RMSEP), coefficient of determination $\left(R^{2}\right)$, root

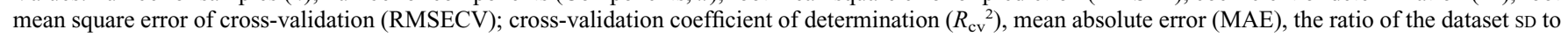
RMSEP (RPD), and the ratio of the dataset interquartile range to RMSEP (RPIQ).

Table 4. Regression statistics of "Whole-Fruit" dry matter (DM) and soluble solids content (SSC) against blush, shade, and average of blush and shade DM and SSC destructive determination and near-infrared (NIR) estimation in pooled d'Anjou and Bartlett calibration datasets.

\begin{tabular}{|c|c|c|c|c|c|c|c|}
\hline \multirow[b]{2}{*}{ Parameter } & \multirow[b]{2}{*}{ Statistic } & \multicolumn{3}{|c|}{ Destructive determination } & \multicolumn{3}{|c|}{ NIR estimation } \\
\hline & & Blush DM & Shade DM & Avg blush/shade DM & $\overline{\text { Blush DM }}$ & Shade DM & Avg blush/shade DM \\
\hline \multirow[t]{3}{*}{ "Whole-Fruit" DM } & $R^{2}$ & 0.964 & 0.966 & 0.979 & 0.948 & 0.958 & 0.974 \\
\hline & RMSE & 0.539 & 0.458 & 0.386 & 0.631 & 0.475 & 0.402 \\
\hline & $\mathrm{MAE}^{* * *}$ & $0.473(\mathrm{~A})$ & $0.520(\mathrm{~A})$ & $0.349(\mathrm{~B})$ & $0.553(\mathrm{~A})$ & $0.510(\mathrm{~A})$ & $0.375(\mathrm{~B})$ \\
\hline Parameter & Statistic & Blush SSC & Shade SSC & Avg blush/shade SSC & Blush SSC & Shade SSC & Avg blush/shade SSC \\
\hline \multirow[t]{3}{*}{ "Whole-Fruit" SSC } & $R^{2}$ & 0.964 & 0.958 & 0.981 & 0.950 & 0.955 & 0.970 \\
\hline & RMSE & 0.527 & 0.485 & 0.353 & 0.630 & 0.512 & 0.451 \\
\hline & $\mathrm{MAE}^{* * *}$ & $0.426(\mathrm{~A})$ & $0.470(\mathrm{~A})$ & $0.347(\mathrm{~B})$ & $0.519(\mathrm{~A})$ & $0.518(\mathrm{~A})$ & $0.399(\mathrm{~B})$ \\
\hline
\end{tabular}

Values: coefficient of determination $\left(R^{2}\right)$; root mean square error (RMSE); and mean absolute error (MAE). Similar letters indicate nonstatistically significant different means as determined by Student-Newman-Keuls test.

$* P<0.05, * * P<0.01$, or $* * * P<0.001$.

Table 5. Performance statistics for dry matter (DM) and soluble solids content (SSC) models developed for d'Anjou and Bartlett pear applied to external validation datasets (Orchards 1, 2, and 3 consisting of d'Anjou/OHF87, d'Anjou/Bartlett seedling, and Bartlett/OHF87, respectively) evaluated at harvest (less than 1 month of cold storage) or poststorage ( 6 month of regular atmosphere cold storage).

\begin{tabular}{|c|c|c|c|c|c|c|c|c|c|c|c|c|c|c|c|}
\hline \multirow[b]{2}{*}{ Cultivar } & \multirow[b]{2}{*}{ Validation set } & \multirow[b]{2}{*}{ Model } & \multirow[b]{2}{*}{ Fruit maturity } & \multicolumn{6}{|c|}{ DM (\%) } & \multicolumn{6}{|c|}{$\mathrm{SSC}(\%)$} \\
\hline & & & & $n$ & RMSEP & $R^{2}$ & MAE & RPD & RPIQ & $n$ & RMSEP & $R^{2}$ & MAE & RPD & RPIQ \\
\hline \multirow[t]{6}{*}{$\overline{\text { Bartlett }}$} & \multirow[t]{6}{*}{ Orchard 3} & \multirow[t]{3}{*}{ Bartlett } & Pooled & 120 & 0.781 & 0.777 & 0.688 & 2.107 & 3.242 & 382 & 0.686 & 0.774 & 1.261 & 2.102 & 2.914 \\
\hline & & & At-harvest & 60 & 0.732 & 0.733 & 0.963 & 1.920 & 2.594 & 197 & 0.687 & 0.726 & 1.552 & 1.906 & 2.619 \\
\hline & & & Poststorage & 60 & 0.415 & 0.921 & 0.413 & 3.517 & 5.724 & 185 & 0.535 & 0.855 & 0.952 & 1.398 & 2.615 \\
\hline & & \multirow[t]{3}{*}{ d'Anjou } & Pooled & 120 & 0.779 & 0.777 & 0.836 & 2.110 & 3.248 & 382 & 0.706 & 0.761 & 0.799 & 2.044 & 2.834 \\
\hline & & & At-harvest & 60 & 0.719 & 0.743 & 0.526 & 1.955 & 2.642 & 197 & 0.703 & 0.714 & 0.696 & 1.864 & 2.561 \\
\hline & & & Poststorage & 60 & 0.581 & 0.845 & 1.146 & 2.515 & 4.094 & 185 & 0.599 & 0.818 & 0.909 & 2.336 & 3.676 \\
\hline \multirow[t]{12}{*}{ d'Anjou } & \multirow[t]{6}{*}{ Orchard 1} & \multirow[t]{3}{*}{ Bartlett } & Pooled & 203 & 0.836 & 0.722 & 1.918 & 1.879 & 2.586 & 944 & 0.497 & 0.807 & 2.565 & 2.275 & 2.820 \\
\hline & & & At-harvest & 108 & 0.692 & 0.813 & 2.514 & 2.300 & 2.969 & 487 & 0.487 & 0.821 & 2.498 & 2.359 & 3.077 \\
\hline & & & Poststorage & 95 & 0.405 & 0.914 & 1.239 & 3.396 & 4.448 & 457 & 0.494 & 0.790 & 2.637 & 2.177 & 2.632 \\
\hline & & \multirow[t]{3}{*}{ d'Anjou } & Pooled & 203 & 0.709 & 0.799 & 0.581 & 2.214 & 3.046 & 944 & 0.517 & 0.791 & 0.398 & 2.186 & 2.709 \\
\hline & & & At-harvest & 108 & 0.663 & 0.821 & 0.767 & 2.400 & 3.097 & 487 & 0.469 & 0.834 & 0.365 & 2.452 & 3.199 \\
\hline & & & Poststorage & 95 & 0.434 & 0.901 & 0.369 & 3.162 & 4.142 & 457 & 0.546 & 0.743 & 0.432 & 1.969 & 2.380 \\
\hline & \multirow[t]{6}{*}{ Orchard 2} & \multirow[t]{3}{*}{ Bartlett } & Pooled & 75 & 0.742 & 0.874 & 1.830 & 2.778 & 4.819 & 217 & 0.762 & 0.826 & 2.691 & 2.384 & 3.543 \\
\hline & & & At-harvest & 45 & 0.444 & 0.960 & 2.274 & 4.924 & 7.898 & 126 & 0.891 & 0.814 & 2.708 & 2.306 & 3.366 \\
\hline & & & Poststorage & 30 & 0.482 & 0.931 & 1.163 & 3.739 & 5.579 & 91 & 0.501 & 0.881 & 2.666 & 2.883 & 4.390 \\
\hline & & \multirow[t]{3}{*}{ d'Anjou } & Pooled & 75 & 0.659 & 0.900 & 0.537 & 3.148 & 5.426 & 217 & 0.722 & 0.843 & 0.562 & 2.522 & 3.740 \\
\hline & & & At-harvest & 45 & 0.462 & 0.957 & 0.508 & 4.737 & 7.599 & 126 & 0.816 & 0.843 & 0.626 & 2.517 & 3.675 \\
\hline & & & Poststorage & 30 & 0.570 & 0.903 & 0.581 & 3.157 & 4.711 & 91 & 0.568 & 0.847 & 0.472 & 2.542 & 3.871 \\
\hline \multirow[t]{6}{*}{ d'Anjou \& Bartlett } & \multirow[t]{6}{*}{ Pooled } & \multirow[t]{3}{*}{ Bartlett } & Pooled & 398 & 1.078 & 0.666 & 1.530 & 1.728 & 2.273 & 1,543 & 0.843 & 0.651 & 2.260 & 1.691 & 2.135 \\
\hline & & & At-harvest & 213 & 0.967 & 0.706 & 2.027 & 1.840 & 2.202 & 810 & 0.801 & 0.670 & 2.301 & 1.740 & 2.246 \\
\hline & & & Poststorage & 185 & 0.773 & 0.800 & 0.959 & 2.230 & 2.884 & 733 & 0.883 & 0.635 & 2.215 & 1.655 & 2.039 \\
\hline & & \multirow[t]{3}{*}{ d'Anjou } & Pooled & 398 & 0.821 & 0.806 & 0.649 & 2.268 & 2.983 & 1,543 & 0.683 & 0.770 & 0.520 & 2.087 & 2.634 \\
\hline & & & At-harvest & 213 & 0.747 & 0.825 & 0.644 & 2.381 & 2.850 & 810 & 0.651 & 0.782 & 0.486 & 2.141 & 2.764 \\
\hline & & & Poststorage & 185 & 0.653 & 0.858 & 0.655 & 2.642 & 3.417 & 733 & 0.714 & 0.762 & 0.558 & 2.046 & 2.521 \\
\hline
\end{tabular}

Values: number of samples $(n)$; coefficient of determination $\left(R^{2}\right)$, root mean square error of prediction (RMSEP), mean absolute error (MAE), the ratio of the dataset SD to RMSEP (RPD), and the ratio of the dataset interquartile range to RMSEP (RPIQ).

light interception across the individual fruit as well. Differences appear relatively consistent throughout the range of "Whole-Fruit" DM and SSC, indicating the strength of the gradient does not diminish at higher levels of postharvest DM and SSC. The divergence in values on opposing sides directly translated into divergence of the NIR predictions on those sides, with differences reaching more than $3.5 \%$ and $2.9 \%$ of DM and SSC, respectively. The best estimation of "Whole-Fruit" DM or SSC was consis- tently obtained by averaging measurements from opposing sides. In respect to NIR model development, consideration should be taken in selecting the area for spectra acquisition and reference sampling, as DM and SSC values can vary drastically between fruit sides, which will in turn affect model calibration.

\section{Conclusion}

The main objective of this study was to evaluate whether NIR spectroscopy could be used as a reliable predictor of DM and SSC in d'Anjou and Bartlett pears using a commercially available NIR spectrometer. We have demonstrated that acceptable models can be developed for use across multiple stages of postharvest ripeness, pear cultivars, and temperatures. Discrepancies between DM and SSC values in fruit used in calibration and fruit used in external cross-validation was a large component of overall model performance. Fruit maturity at the time of calibration also affects model performance when applied to fruit of differing levels of postharvest maturity. Thus, 

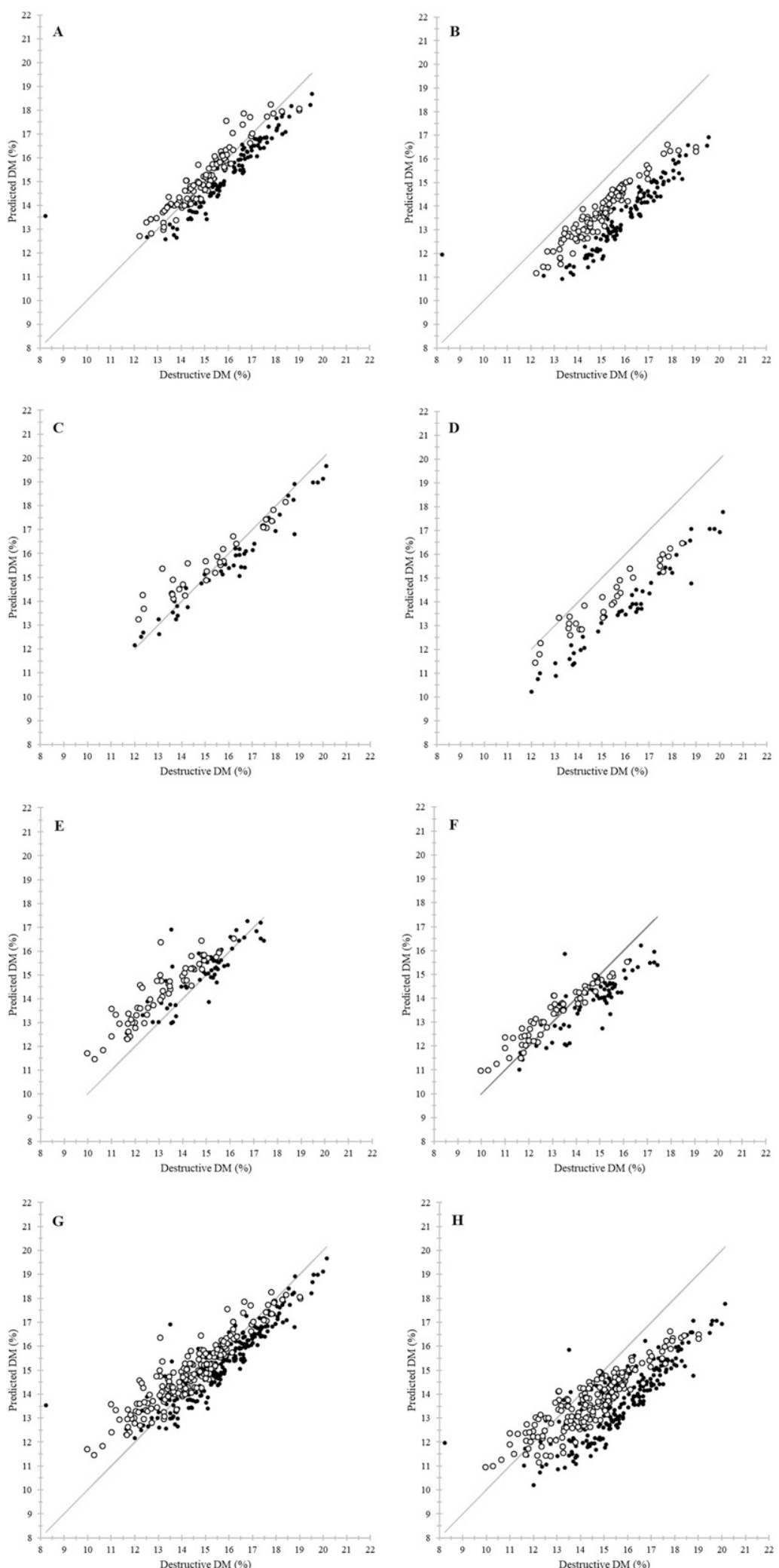

Fig. 8. Destructive vs. predicted dry matter (DM, \%) values among external validation sets as estimated by d'Anjou or Bartlett model at harvest (solid black points) or after 6 months of regular atmosphere cold storage (hollow white points). (A) Orchard 1 (d'Anjou/OHF87) DM as predicted by d'Anjou model, (B) Orchard 1 (d'Anjou/OHF87) DM as predicted by Bartlett model, (C) Orchard 2 (d'Anjou/Bartlett seedling) DM as predicted by d'Anjou model, (D) Orchard 2 (d'Anjou/Bartlett seedling) DM as predicted by Bartlett model, (E) Orchard 3 (Bartlett) DM as predicted by d'Anjou model, (F) Orchard 3 (Bartlett/OHF87) DM as predicted by Bartlett model, (G) Pooled external validation DM as predicted by d'Anjou model, and (H) Pooled external validation DM as predicted by Bartlett model. Reference lines illustrate a 1:1 prediction of the destructive value. extensive cross-validation using externally sourced datasets is highly recommended to test whether models perform as expected beyond calibration. In addition, because of large deviations in absorbance evident among fruit temperatures at several wavelengths owing to the absorption response of water, temperature should be thoughtfully considered in the construction of any NIR model, as implementation of a model outside of its calibration environment will undoubtedly have negative impacts on model performance. The placement of the NIR sensor on the fruit may also affect model development, as we observed strong equatorial gradients DM and SSC values from blush to shade side of the fruit. In application, averaged NIR estimations of the same fruit from opposing sides provides a more accurate depiction of whole-fruit DM and SSC.

\section{Literature Cited}

Anderson, N.T., P.P. Subedi, and K.B. Walsh. 2017. Manipulation of mango fruit dry matter content to improve eating quality. Scientia Hort. 226:316-321.

Bellon-Maurel, V., E. Fernandez-Ahumada, B. Palagos, J.M. Roger, and A. McBratney. 2010. Critical review of chemometric indicators commonly used for assessing the quality of the prediction of soil attributes by NIR spectroscopy. Trends Anal. Chem. 29(9):10731081.

Crisosto, G., J. Hasey, J. Zegbe, and C. Crisosto. 2012. New quality index based on dry matter and acidity proposed for Hayward kiwifruit. Calif. Agr. 66(2): 70-75.

dos Santos, C.A.T., M. Lopo, R.N. Páscoa, and J.A. Lopes. 2013. A review on the applications of portable near-infrared spectrometers in the agro-food industry. Appl. Spectrosc. 67(11): 1215-1233.

Escribano, S., W.V. Biasi, R. Lerud, D.C. Slaughter, and E.J. Mitcham. 2017. Non-destructive prediction of soluble solids and dry matter content using NIR spectroscopy and its relationship with sensory quality in sweet cherries. Postharvest Biol. Technol. 128:112120.

Gamble, J., F.R. Harker, S.R. Jaeger, A. White, C. Bava, M. Beresford, B. Stubbings, M. Wohlers, P.J. Hofman, R. Marques, and A. Woolf. 2010 The impact of dry matter, ripeness and internal defects on consumer perceptions of avocado quality and intentions to purchase. Postharvest Biol. Technol. 57(1):35-43.

Golic, M., K. Walsh, and P. Lawson. 2003. Shortwavelength near-infrared spectra of sucrose, glucose, and fructose with respect to sugar concentration and temperature. Appl. Spectrosc. 57(2):139-145.

Harker, F.R., B.T. Carr, M. Lenjo, E.A. MacRae, W.V. Wismer, K.B. Marsh, and F.A. Gunson. 2009. Consumer liking for kiwifruit flavour: A meta-analysis of five studies on fruit quality. Food Qual. Prefer. 20(1):30-41.

Jaeger, S.R., R. Harker, C.M. Triggs, A. Gunson, R.L. Campbell, R. Jackman, and C. RequejoJackman. 2011. Determining consumer purchase intentions: The importance of dry matter, size, and price of kiwifruit. J. Food Sci. 76(3):S177-S184.

Kawano, S., H. Abe, and M. Iwamoto. 1995. Development of a calibration equation with temperature compensation for determining the Brix value in intact peaches. J. Near Infrared Spectrosc. 3:211-218. 

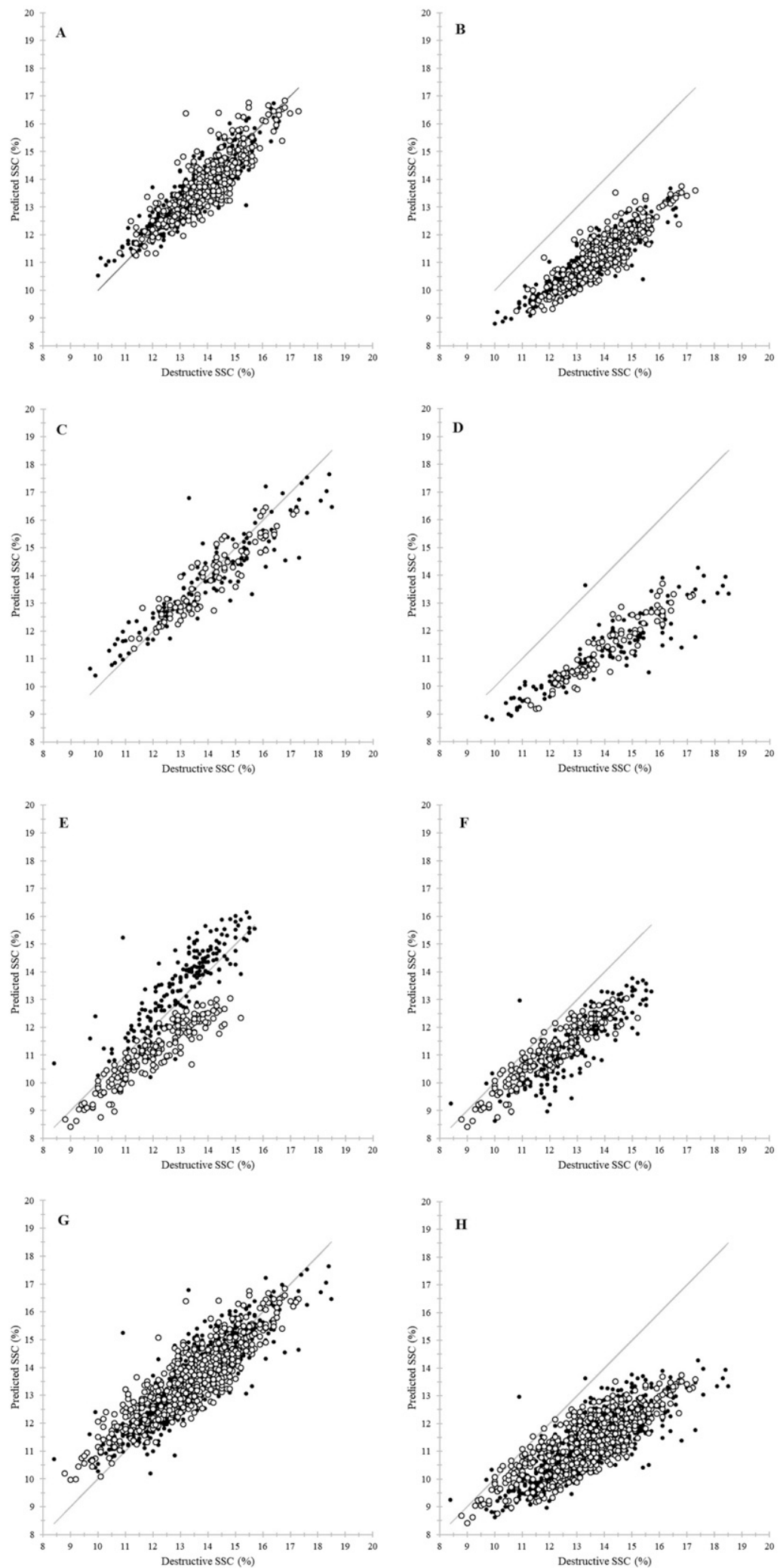

Fig. 9. Destructive vs. predicted soluble solids content (SSC, \%) values among external validation sets as estimated by d'Anjou or Bartlett model at harvest (solid black points) or after 6 months of regular atmosphere cold storage (hollow white points). (A) Orchard 1 (d'Anjou/OHF87) SSC as predicted by d'Anjou model, (B) Orchard 1 (d'Anjou/OHF87) SSC as predicted by Bartlett model, (C) Orchard 2 (d'Anjou/Bartlett seedling) SSC as predicted by d'Anjou model, (D) Orchard 2 (d'Anjou/Bartlett seedling) SSC as predicted by Bartlett model, (E) Orchard 3 (Bartlett) SSC as predicted by d'Anjou model, (F) Orchard 3 (Bartlett/OHF87) SSC as predicted by Bartlett model, (G) Pooled external validation SSC as predicted by d'Anjou model, and (H) Pooled external validation SSC as predicted by Bartlett model. Reference lines illustrate a 1:1 prediction of the destructive value.
Kupferman, E., K. Gallardo, C. Sater, and A. Colonna. 2010. Conditioning 'Anjou' pears to meet consumer quality demands. Acta Hort. 880:105-109.

McGlone, V.A. and S. Kawano. 1998. Firmness, dry-matter and soluble-solids assessment of postharvest kiwifruit by NIR spectroscopy. Postharvest Biol. Technol. 13(2):131-141.

McGlone, V.A., C.J. Clark, and R.B. Jordan. 2007. Comparing density and VNIR methods for predicting quality parameters of yellowfleshed kiwifruit (Actinidia chinensis). Postharvest Biol. Technol. 46(1):1-9.

McGlone, V.A., R.B. Jordan, and P.J. Martinsen. 2002a. Vis/NIR estimation at harvest of preand post-storage quality indices for 'Royal Gala'apple. Postharvest Biol. Technol. 25(2): 135-144.

McGlone, V.A., R.B. Jordan, R. Seelye, and C.J. Clark. 2003. Dry-matter-A better predictor of the post-storage soluble solids in apples? Postharvest Biol. Technol. 28(3):431-435.

McGlone, V.A., R.B. Jordan, R. Seelye, and P.J. Martinsen. 2002b. Comparing density and NIR methods for measurement of Kiwifruit dry matter and soluble solids content. Postharvest Biol. Technol. 26(2):191-198.

McGuire, R.G. 1992. Reporting of objective color measurements. HortScience 27:1254 1255.

Nicolai, B.M., K. Beullens, E. Bobelyn, A. Peirs, W. Saeys, K.I. Theron, and J. Lammertyn. 2007. Nondestructive measurement of fruit and vegetable quality by means of NIR spectroscopy: A review. Postharvest Biol. Technol. 46(2):99-118.

Osborne, S.D., R.B. Jordan, and R. Künnemeyer. 1996. Using near-infrared (NIR) light to estimate the soluble solids and dry matter content of kiwifruit. Acta Hort.464:109114

Pacific Northwest Pear Research Committee. 2016. PNW pear research priorities for 2017. 17 Aug. 2017. <http://www.treefruitresearch.com/images/ PEAR_RESEARCH_PRIORITIES_FOR_2017. pdf $>$.

Palmer, J.W., F.R. Harker, D.S. Tustin, and J. Johnston. 2010. Fruit dry matter concentration: A new quality metric for apples. J. Sci. Food Agr. 90(15):2586-2594.

Peiris, K.H.S., G.G. Dull, R.G. Leffler, and S.J. Kays. 1999. Spatial variability of soluble solids or dry-matter content within individual fruits, bulbs, or tubers: Implications for the development and use of NIR spectrometric techniques. HortScience 34:114-118.

Perring, M.A. 1989. Changes in dry matter concentration gradients in stored apples. J. Sci. Food Agr. 46(4):439-449.

Rudell, D.R., S. Serra, N. Sullivan, J.P. Mattheis, and S. Musacchi. 2017. Survey of 'd'Anjou' pear metabolic profile following harvest from different canopy positions and fruit tissues. HortScience 52:1501-1510.

Saranwong, S. and S. Kawano. 2007. Fruits and vegetables, p. 219-245. In: Y. Ozaki, W.F. McClure, and A.A. Christy (eds.). Nearinfrared spectroscopy in food science and technology. John Wiley \& Sons, Inc., Hoboken, NJ.

Subedi, P., K. Walsh, and P. Purdy. 2010. Determination of optimum maturity stages of mangoes using fruit spectral signatures. IX Intl. Mango Symp. 992:521-527.

Subedi, P.P., K.B. Walsh, and G. Owens. 2007. Prediction of mango eating quality at harvest using short-wave near infrared spectrometry. Postharvest Biol. Technol. 43(3):326-334. 
Suni, M., M. Nyman, N.A. Eriksson, L. Björk, and I. Björck. 2000. Carbohydrate composition and content of organic acids in fresh and stored apples. J. Sci. Food Agr. 80(10):1538-1544.

Toivonen, P., A. Batista, and B. Lannard. 2017. Development of a predictive model for 'Lapins' sweet cherry dry matter content using a visible/near infrared spectrometer and its potential application to other cultivars. Can. J. Plant Sci. 97(6):1030-1035.

Torres, C.A., A. Sepulveda, J. Gonzalez-Talice, J.A. Yuri, and I. Razmilic. 2013. Fruit water relations and osmoregulation on apples (Malus domestica Borkh.) with different sun exposures and sun-injury levels on the tree. Scientia Hort. 161:143-152.

Travers, S., M.G. Bertelsen, and S.V. Kucheryavskiy. 2014a. Predicting apple (cv. Elshof) postharvest dry matter and soluble solids content with near infrared spectroscopy. J. Sci. Food Agr. 94 (5):955-962.

Travers, S., M.G. Bertelsen, K.K. Petersen, and S.V. Kucheryavskiy. 2014b. Predicting pear (cv. Clara Frijs) dry matter and soluble solids content with near infrared spectroscopy. Lebensm. Wiss. Technol. 59(2):1107-1113.
Wang, H., J. Peng, C. Xie, Y. Bao, and Y. He. 2015. Fruit quality evaluation using spectroscopy technology: A review. Sensors 15(5):1188911927.

Zhang, J., S. Serra, R.S. Leisso, and S. Musacchi. 2016. Effect of light microclimate on the quality of ' $d$ 'Anjou' pears in mature open-centre tree architecture. Biosyst. Eng. 141:1-11.

Ziosi, V., M. Noferini, G. Fiori, A. Tadiello, L. Trainotti, G. Casadoro, and G. Costa. 2008. A new index based on vis spectroscopy to characterize the progression of ripening in peach fruit. Postharvest Biol. Technol. 49(3):319-329. 